\title{
Landscapes of Knowledge and Innovative Learning Experiences
}

\author{
Massimo Faiferri and Samanta Bartocci
}

\begin{abstract}
In these historic times, when there is a crucial shift in the way we consider the cultural and architectural aspects of learning spaces, it is important to investigate the role this spatial resource plays in the urban context. This, so we can understand the need to break with the outdated ideas about school that are deeply rooted in our society. There is common ground between architecture and pedagogy, a possible dialogue between space and knowledge, which can generate new explorations into the ordinary meaning of educational spaces and landscapes of knowledge, as a chance to expand the concept of inhabiting a space and how that impacts the world, and to devise a new urban condition. By first considering cities as a broad, extended learning space, we provide a chance and an incentive to reflect on the role of spatial design. The city is an important educational tool, since it represents a space of discovery, growth, socialization, tension, conflict and adventure. It is also where autonomy, adaptive intelligence and relational skills are developed. A new relationship between school and the city defines the future of learning and civilized co-existence.
\end{abstract}

Keywords Exploration - Active learning • Urban learning • Urban relations • Landscape of knowledge $\cdot$ Educational spaces

If we leave behind the comfort zone that brought us to the preordained conclusions we are used to, and we open up to reality without any prejudice, we will find that our perception of the world does not have an abstract point of view in the background, but is embodied in the observer. In this way, we take possession of the visible, meaning we can get rid of the dual concept of school-city, by devising a school that can be inhabited [1], or the concept of making school [2]; we can do this by moving away from the physical dimension of the building to the urban space, thus finding many similarities between how they are organized (streets/corridors, classroom/home, plazas/agora etc....).

\section{Faiferri $(\bowtie) \cdot$ S. Bartocci}

Department of Architecture, Design and Urban Planning, University of Sassari, Sassari, Italy e-mail: faiferri@uniss.it 
Much more important is the change in direction towards children and the city, that is, growing up in an urban environment [3], the city as a classroom [4] and the educating city [5].

Instead of school there is the city; it can enhance educating spaces and become a connecting place and a platform for open learning. Another important aspect to highlight on this premise is the following: if it is necessary to place the content of knowledge into specific settings that are expressly designed for that purpose, and structured according to a complex system and "intelligence" that grows with children's ability to "inhabit" and "use" them to learn how to learn, then experience, consisting of actions and choices, has a continuous relationship with the physical environment. For this reason, it is accepted that buildings express the values and the attitudes of their designer; but it is less evident, or less well known, the way in which buildings and space will affect users [6].

Psychological research demonstrates this need by recognizing space as an existential and experienced dimension [7], considering it a reference point of the identity of human experience [8]; even proxemics research has proven the strong influence of space on individuals' behavior [9], identifying empathy as the cognitive ability that makes people perceive other individuals' sensations, experiencing their resonance, and, finally, activating cognitive processes [10].

We look, touch, listen and measure the world with our whole bodies, and we structure the perceivable world around our bodies, which we consider to be the central element.

The body plays a fundamental role in the construction of the mental representation of ourselves, which will never be definitive, but will change continuously for the rest of our lives. We constantly understand and learn through the senses, defining the feeling of belonging to a space, a place, or a community.

It is a scientific certainty that the development of cognitive abilities occurs through the body, particularly through the experiences that children have with their body actions.

Action represents the fundamental element for attaining any kind of learning.

The relationship between single actions or more complex patterns of action creates the conditions for defining an organization of one self's acting, based on the experiences transferred from other situations or directed to the organization of new actions. Thus, all possible access routes to knowledge begin with the body, and body action is necessary for the development of cognitive processes.

Guiding space design towards a sense of possible action means being in the movement of choice, as an open process of subjective representation of reality. When we talk about "spaces inviting to action" we are thinking about a generative action as a new approach to design. A new connection between school and city defines the future of learning and civil co-existence and, as said above, evokes the metaphor of the "school as city", that is, a microcosm where corridors recall streets, classrooms recall buildings, spaces for socialization and leisure recall urban squares. This metaphor becomes more interesting and innovative when we reverse it: instead of a school there is a city, a city that turns into a school, animated by educational spaces, a place for learning that is open to a landscape of knowledge. This point of view 
leads us to consider the investigation of the Ecourbanlab research group ${ }^{1}$ of the Department of Architecture, Design and Urban Planning, (DADU) of the University of Sassari, through the activities of the International Scientific School held since 2016 at the "Parco Scientifico e Tecnlogico di Porto Conte Ricerche" in Alghero, on the topic of Innovative Learning Spaces (ILS). In this research, the Scientific Schools ${ }^{2}$ have become the field of investigation into how learning takes place (not only in schools) in contemporary society; every year the ILS scientific board has defined different objectives according to specific detailed topics, closely related to strategies of international research and regional planning.

The experiences over the last years have given rise to an executive board on which international professionals from all over the world have been involved in investigating the relationships between space design, pedagogy, energy, use of materials, computer science, physics, and new technologies. This provides an opportunity to experience the complexity of educational paths and, at the same time, find a way to renew the concept of school within an extended landscape of learning.

During the first edition of the scientific school, this approach was focused mainly on the design of school spaces, both new and existing ones.

In the second edition, the discussion was broadly on the synergy between the web and the possibility of integrating it with physical places and urban spaces, through augmented reality. The topic of the third edition introduced the principle that takes us from the school-based, urban and public learning space to "a city for everyone". This issue is not merely about disability, but rather it aims to explore, in technological and spatial terms, all the possible tools and facilitative solutions, in order to ensure the mechanisms of learning are spontaneous and inclusive for every citizen. The results of the school activities point out how the new ways of socializing and learning, supported by ICT and virtual reality, leads to inclusion being the main strategy that retains the ability to defend the local context [11]. Thus the urban context is the place where every inhabitant plays into an inclusive space based on sharing. The fourth edition of the International Scientific School, held in 2019, aimed to promote a high-value scientific and educational initiative to open up opportunities for dialogue among researchers, working every day in research spaces, and space

\footnotetext{
${ }^{1}$ Ecourbanlab is a research laboratory in the Department of Architecture, Design and Urban planning of the University of Sassari focused on space design as an investigative and testing tool of urban complexity. It analyzes and looks into several fundamental issues of the contemporary city, such as collective housing, urban re-use and renovation, and innovative learning spaces. Ecourbanlab is supervised by Professor Massimo Faiferri in collaboration with Samanta Bartocci, Fabrizio Pusceddu, Lino Cabras, Laura Pujia, and Rosa Manca.

${ }^{2}$ The Scientific schools Innovative Learning Spaces are organized by DADU (Department of Architecture, Design and Planning, University of Sassari within the SPIN-APP project); Innovative Spaces for Learning (Regional Law n.7, "Promotion of scientific research and technological innovation in Sardinia"), in collaboration with the INFN—Frascati (National Institute of Nuclear Physics, with the contribution of Sardegna Ricerche under the Scientific Schools project. The Scientific Schools are supervised by Prof. Massimo Faiferri.

Websites: http://ils2016.wixsite.com/uniss, http://ils2017.wixsite.com/uniss, https://ils2018sc hool.wixsite.com/uniss, https://ils2019school.wixsite.com/uniss.
} 
designers, while fostering a cross-pollination between the two fields of investigation. Research infrastructures are defined as facilities, resources or services used by researchers or companies for doing scientific research or enhancing knowledge and innovation. Research infrastructures can be great equipment, data archives, electronic devices or other kinds of structures. They can be precisely located, distributed in space or virtually defined: regardless of their nature, a research infrastructure is a form of excellence in terms of knowledge and innovation. The question we asked ourselves is: how can we find a connection between all these high-profile scientific activities and the local communities, in order to enhance local knowledge within a process of development for society and the economy? The dimension that relates to scale of knowledge aims to establish a reference range, by defining a set of problems, questions, needs and opportunities for which public policy and space organization can find an answer. Here the goal is to define the boundaries (both symbolically and geographically) of public action regarding space, where "boundaries" means "mobile borders" that can be changed as and when necessary. Thus, we can find a relationship between the scale of the abstract structure of knowledge and the organization of spaces for knowledge, from the formal institutions of learning to the territorial dimension. Therefore, we define a new urban and territorial morphology that assesses physical places according to their capacity for teaching, the interactions they promote, and the opportunities they offer for creating groups and enabling creativity. Ingold's [12] anthropological vision has provoked the transition from the concept of living in the world (dwelling) to one of living with the world (inhabiting). The phrase "interaction between perception and environment", often quoted as a way of describing potentially innovative learning spaces, presents a dichotomy between constructing and dwelling. This clarifies the vision of inhabiting as the sensation of feeling at home. This self-awareness opens up a pathway of re-imagination, which takes us from a conventional school space-or an unconventional one-to a wider vision and the spaces of research infrastructures. For the user, this awareness means choosing how to inhabit space, considering the idea that we do not move within a defined or static environment, but rather one that is "made" and is continuously refashioned.

The ILS Scientific school has worked locally to identify new learning territories, and has recognized public spaces and the public dimensions of the territory as learning spaces, for the areas identified in Sardinia Region's Smart Specialization Strategy (S3) for "Intelligent, sustainable and inclusive growth". A theater, a garden, a square, a church, a museum, a park, a former mine or an industrial building, for instance, retain certain features which, if properly reconsidered through space design, can transform ordinary, everyday places into devices for enhancing knowledge. Every place has its specific qualities, which are often not immediately or spontaneously 
readable. Hence, the research aims to use these traits to identify subjects for scientific publications and results, such as a network of "active spaces", directed at different levels of design (i.e., simply opening them up and making them available, making small changes to ensure they can actually be used, or setting up ad hoc installations). Augmented reality can link these places so they can share experiences and create a "connective urban learning platform". 3 These experiments-conducted in the form of workshops - have been an opportunity to test and adjust the ongoing scientific research. The outcome of these experiments is that they later formed the basis of important research projects, like those funded by the PRIN program, ${ }^{4}$ and framework agreements between institutions. Furthermore, the research results have been published at exhibitions, conferences and in international scientific publications. In conclusion, the focus of research on architecture and learning is whether or not these spaces can be used as platforms of dialogue between public administrations and citizens, across different generations, cultures and institutions; whether they can share the same spaces and the same dynamics of innovation as museums, universities, research centers, and cultural and sports centers.

\section{References}

1. Ingold T.: The Perception of the Environment: Essays on Livelihood, Dwelling and Skill, Routledge, London (2000)

2. Weyland, B.: Fare scuola. Un corpo da reinventare, Guerini, Milano (2014)

3. Ward, C.: Il bambino e la città. Crescere in ambiente urbano, L'ancora del mediterraneo, Napoli (2000.)

4. Brusa, A., Borri, D., Porsia, F.: La città come aula, Edipuglia, Bari (1985).

5. Clemente, F.: I contenuti formativi della città ambientale, Pacini, Pisa (1974)

6. Plummer, H.: L'esperienza dell'architettura. Einaudi, Torino (2016)

7. Iori, V.: Lo spazio vissuto, Firenze, La nuova Italia, Firenze (1999)

8. Hillman J.: L'anima dei luoghi, Rizzoli, Milano (2004)

9. Costa, M.: Psicologia ambientale e Architettonica, Franco Angeli, Milano (2009)

10. Sinigaglia C., Rizzolati G.: So quel che fai. Il cervello che agisce e i neuroni specchio, Raffaello Cortina Editore, Milano (2006)

11. Tagliagambe, S.: Idea di scuola, Tombolini, Ancona (2016)

12. Ingold, T.: Ecologia della cultura, Meltemi, Milano (2001)

\footnotetext{
${ }^{3}$ A demo web platform has been developed from this concept, which looks at the city's broad potential as a learning space.

${ }^{4}$ See the PRIN project (Research Projects of National Interest) titled "PROtotypes of Schools to be lived-PROSE new architectural models for the construction, the renovation and resilient recovery of school buildings and to build the future in Italy." (Scientific Director Professor Massimo Faiferri, with the research laboratory ecourbanlab - partner of Frascati Scienza), and the "European Researchers' Night" project funded by the European Commission Horizon 2020IMarie Skłodowska-Curie (GA No. 818728).
} 
Open Access This chapter is licensed under the terms of the Creative Commons Attribution 4.0 International License (http://creativecommons.org/licenses/by/4.0/), which permits use, sharing, adaptation, distribution and reproduction in any medium or format, as long as you give appropriate credit to the original author(s) and the source, provide a link to the Creative Commons license and indicate if changes were made.

The images or other third party material in this chapter are included in the chapter's Creative Commons license, unless indicated otherwise in a credit line to the material. If material is not included in the chapter's Creative Commons license and your intended use is not permitted by statutory regulation or exceeds the permitted use, you will need to obtain permission directly from the copyright holder.

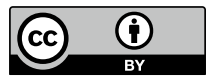

